\title{
0 Enem é uma avaliação educacional construtivista? Um estudo de validade de construto ${ }^{1}$
}

\section{CRISTIANO MAURO ASSIS GOMES}

OTO BORGES ${ }^{*}$

\section{RESUMO}

O Exame Nacional do Ensino Médio (Enem) propóe mensurar modalidades estruturais da inteligência mediante uma concepção construtivista com amplo foco na resoluçáo de problemas. Apesar de suas inovaçóes, o Exame ainda não passou por um estudo de validade de construto, para verificar se ele, de fato, ativa processos cognitivos enfatizados por seu modelo. Este artigo, portanto, apresenta um estudo exploratório de validade de construto desse instrumento. Foram aplicados 45 testes de inteligência, assim como a prova objetiva de 2001 do Enem, a 146 estudantes do terceiro ano de uma escola de ensino médio da rede federal. Realizou-se uma regressão stepwise entre as habilidades cognitivas e o escore dos estudantes no Enem. O desempenho no Exame foi fortemente explicado pelas habilidades cognitivas (60\%), por meio da resoluçáo de problemas, da rapidez cognitiva e da compreensão verbal. O Enem mostrou-se um bom instrumento construtivista para fins educacionais.

Palavras-chave: Enem, avaliação da educação, ensino médio, avaliação da aprendizagem.

\footnotetext{
${ }^{1}$ Os dados discutidos neste artigo são provenientes da tese de doutorado de Gomes (2005).

* Professor adjunto do Departamento de Psicologia da Universidade Federal de Minas Gerais (cristianogomes@ufmg.br).

** Professor associado do Departamento de Física da Universidade Federal de Minas Gerais, professor do Colégio Técnico de Minas Gerais e Coordenador do Programa de Pós-Graduação em Educação da Universidade Federal de Minas Gerais (oto@coltec.ufmg.br).
} 


\section{RESUMEN}

El Examen Nacional de la Enseñanza Media (Enem) propone medir las modalidades estructurales de la inteligencia por medio de una concepción constructivista con un amplio enfoque en la resolución de problemas. A pesar de las innovaciones, el Enem todavía no ha pasado por un estudio de validez de constructo para verificar si efectivamente activa procesos cognoscitivos definidos por su modelo. Este artículo, por lo tanto, presenta un estudio que explora la validez de constructo de esta herramienta. Se aplicaron 45 pruebas de inteligencia, así como también la prueba objetiva del Enem del 2001, a 146 alumnos del tercer año de una escuela secundaria dependiente del gobierno federal. Se realizó una regresión stepwise entre las habilidades cognoscitivas y la puntuación obtenida por los alumnos en el Enem. El desempeño en el Examen fue fuertemente explicado por las habilidades cognoscitivas (60\%), la resolución de problemas, la rapidez cognoscitiva y la comprensión verbal. El Enem ha mostrado ser un bueno instrumento constructivista para fines educativos.

Palabras clave: Enem, evaluación de la educación, enseñanza media, evaluación del aprendizaje.

\section{ABSTRACT}

The Enem (National High School Exam) considers measuring structural modalities of intelligence through a constructivist conception with a strong focus on problem solving. Despite its innovations, the Enem has not yet been the object of a study on construct validity, in order to verify if it in fact activates cognitive processes emphasized in its model. This article presents an exploratory study of the Enem construct validity. Forty-five intelligence tests as well as the Enem 2001 objective test were given to 146 students of the third year of a federal high school. A stepwise regression was used between the cognitive abilities and the students' scores in the Enem. The performance in the Enem was largely explained by cognitive abilities (60\%). The abilities responsible for this explanation were Problem Solving, Cognitive Speed and Verbal Comprehension. The Enem proved to be a good constructivist instrument for educational ends.

Keywords: Enem, educational assessment, high school, learning assessment. 


\section{INTRODUÇÃO}

O Exame Nacional do Ensino Médio (Enem) propóe mensurar modalidades estruturais da inteligência, denominadas competências (Brasil, 1998, 2000, 2001). São cinco as modalidades da inteligência focadas pelo Enem que, sucintamente, correspondem à capacidade das pessoas em: 1) operar mentalmente diversas linguagens abstratas e fazer uso delas; 2) utilizar e manipular conceitos e procedimentos específicos para compreender os fenômenos; 3) resolver problemas; 4) discutir e analisar estruturas argumentativas; 5) transformar a teoria em propostas e aplicaçóes prático-concretas (Condeixa et al., 2005; Machado, 2005a,b; Macedo et al., 2005; Martino et al., 2005; Menezes et al., 2005; Murrie, 2005).

O Enem é tido como um exame que segue uma referência teórica construtivista. Suas provas têm sido elaboradas priorizando a resoluçáo de problemas (Macedo, 2005a,b,c). Como decorrência desse foco, outro autor assinala que suas provas náo devem valorizar significativamente a memorizaçáo ou a mera rapidez de pensamento, mas a capacidade dos alunos em relacionar as informaçôes dispostas pelo próprio item. Esse princípio enfatiza a capacidade de o estudante estabelecer novas conexóes para lidar com questóes que sejam verdadeiros desafios (Fini, 2005).

Seguindo esse princípio, portanto, todos os itens do Enem devem pelo menos se aproximar dessa condição (Macedo, 2005a,b,c). Para isso, necessitam fornecer as informaçóes necessárias para que os estudantes possam resolver o problema proposto. O desafio é de o aluno ser capaz de interpretar as informaçóes, saber organizá-las, coordená-las adequadamente e projetar possibilidades, envolvendo o tom da novidade, de modo que os esquemas prévios já aprendidos não determinem totalmente a resolução do problema (Fini, 2005).

Esses argumentos sobre o Enem são interessantes pela ênfase que dão a um tipo de avaliação de determinados processos cognitivos. Se aceitarmos a concepção de competências como modalidades (estruturais) da inteligência, o Enem, ao medir certos aspectos e processos cognitivos relacionados ao desenvolvimento dos estudantes, poderia ser visto como um teste de inteligência, ainda que a serviço da educação.

Levando em consideração suas inovações e tendo em vista os desafios envolvidos, deve-se destacar que o Enem ainda náo passou por um estudo de validade de construto, no sentido de verificar se ele, realmente, ativa os processos cognitivos que enfatiza em seu modelo (Primi et al., 2001). É objeto deste artigo analisar, em 
âmbito exploratório, a validade de construto do Enem. Para isso, selecionamos 45 testes capazes de identificar todos os níveis de habilidades cognitivas do campo psicométrico (Carroll, 1993), de modo a captar as relaçóes existentes entre os diferentes componentes da inteligência e o desempenho dos estudantes no Enem.

Considerando os argumentos pontuados nesta primeira seção, a segunda descreve os métodos, em termos dos participantes, os instrumentos utilizados, as estratégias de análise dos dados e algumas consideraçóes éticas. A terceira aborda os resultados encontrados, e a quarta discute a qualidade do Enem como instrumento de avaliação educacional, assim como aponta algumas implicaçóes para a escola com base nas relaçóes encontradas.

\section{MÉTODO}

\section{Participantes}

São considerados os resultados da aplicação de 45 testes cognitivos e de parte da prova do Enem de 2001, com 63 questóes fechadas, a 146 estudantes pertencentes a oito turmas da terceira série do ensino médio de uma escola da rede federal de ensino: duas eram de 2004 e seis de 2005. Apesar da presença de estudantes nas classes socioeconômicas A, B, C e D, os participantes fazem parte de uma amostra com desempenho escolar superior à média nacional. De maneira geral, as escolas da rede federal de ensino tendem a incorporar um corpo discente com características distintas, do ponto de vista de desempenho cognitivo, da média nacional. Isso pode ser observado ao se comparar o rendimento médio dos participantes da pesquisa na prova do Enem de 2001 e dos estudantes brasileiros. Enquanto a média brasileira de acertos, na prova objetiva, alcançou $40,56 \%$, entre os participantes desta pesquisa ela foi de $64,32 \%$.

\section{Instrumentos}

Foi escolhido o Modelo dos Três Níveis de Habilidades Cognitivas, proposto por Carroll (1993) e exposto de forma sintética na figura 1, por sintetizar as evidências do campo psicométrico sobre as habilidades cognitivas. Esse modelo propóe a existência de três níveis de habilidades cognitivas: o primeiro é composto por habilidades bastante específicas e especializadas; o segundo por habilidades amplas, do tipo pensamento espacial, memória, etc.; e o terceiro pelo Fator Geral (g), ativado por todos os tipos de testes da psicometria. 
Figura 1 - Modelo dos três níveis

de habilidades cognitivas

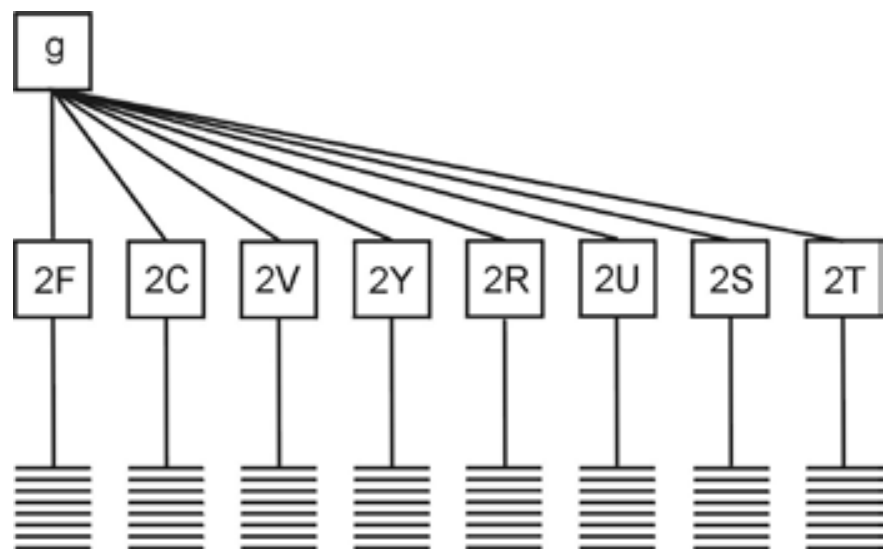

Legenda: $\quad$ g: inteligência geral; $2 \mathrm{~F}$ : inteligência fluida; $2 \mathrm{C}$ : inteligência cristalizada; 2V: habilidade visuoespacial; 2Y: memória; 2R: fluência; $2 \mathrm{U}$ : processamento auditivo; $2 \mathrm{~S}$ : rapidez cognitiva; $2 \mathrm{~T}$ : velocidade de processamento.

Foram traduzidos e adaptados 45 testes do Kit of Factor-Referenced Cognitive Tests do Educational Testing Service. Eles foram selecionados uma vez que possibilitam ao pesquisador identificar um conjunto amplo de habilidades cognitivas dos níveis um, dois e três do modelo de Carroll (1993).

Os testes selecionados, traduzidos e adaptados foram os seguintes: Teste de Figuras Escondidas (CF1), Teste de Padróes Escondidos (CF2), Teste de Cópia (CF3), Teste de Formas (VZ1), Teste de Dobraduras de Papel (VZ2), Teste de Desenvolvimento de Superfícies (VZ3), Palavras Misturadas (CV1), Palavras Escondidas (CV2), Palavras Incompletas (CV3), Teste de Vocabulário Ampliado (V3), Teste de Vocabulário Avançado I (V4), Teste de Vocabulário Avançado II (V5), Teste de Ornamentação (FF1), Teste de Elaboração (FF2), Teste de Símbolos (FF3), Teste de Tópicos (FI1), Teste de Temas (FI2), Teste de Categorias de Objetos (FI3), Teste do Término das Palavras (FW1), Teste do Início das Palavras (FW2), Teste do Início e Término das Palavras (FW3), Teste da Memória de Formas (MV1), Memória de Construçóes (MV2), Memória de Mapas (MV3), Teste Numérico-Figural (MA1), Teste de Numérico-Objeto (MA2), Teste de Nomes e Sobre-Nomes (MA3), Teste de Retenção Auditivo-Numérico (MS1), Teste de Retenção Numérico-Visual (MS2), Teste Auditivo de Retenção de Letras (MS3), 
Teste de Adição (N1), Teste de Multiplicação e Subtração (N3), Correção de Adição e Subtração (N4), Teste "Encontrando a Letra A" (P1), Teste de Comparação Numérica (P2), Teste de Figuras Idênticas (P3), Teste de Aptidão Aritmética (RG1), Teste de Aptidão Matemática (RG2), Teste de Operações Aritméticas Necessárias (RG3). Teste de Silogismos Sem-Sentido (RL1), Representação de Relações (RL2), Teste de Inferências (RL3), Teste dos Arranjos de Letras (I1), Teste das Posições (I2), Classificação de Figuras (I3).

Com relação ao Enem, a prova objetiva (versão amarela) de 2001 foi selecionada aleatoriamente para ser aplicada aos participantes da pesquisa. Apesar da escolha aleatória, é importante salientar que, a partir de 2000, o Enem passou a ser validado por um conjunto de professores, no caráter de juízes, não sendo mais feito um piloto com uma amostragem representativa da população brasileira de estudantes de ensino médio (Brasil, 2001).

\section{Análise dos Dados}

Como a análise do processo de identificação das habilidades cognitivas não é o foco deste artigo, e sim a relação entre elas e o desempenho dos estudantes no Enem, somente será relatado o método de análise dessas relaçóes. Os procedimentos de identificação das habilidades cognitivas são encontrados em Gomes e Borges (2007).

Para identificar as relaçóes entre as habilidades cognitivas e o desempenho dos estudantes no Enem, foi utilizada a técnica stepwise de regressão múltipla, o que permitiu constatar a participação de cada variável cognitiva na explicação da variância do desempenho dos estudantes na prova do Enem.

Foram consideradas variáveis independentes 19 habilidades cognitivas. As de primeiro nível são: Indução-Visualização (I-VZ), Fluência Figural (FF), Compreensão Verbal (V), Memória Associativa (MA), Rapidez Numérica (N), Memória de CurtoTermo (MS), Formação de Palavras (FP), Fluência de Palavras (FW), Raciocínio Geral (RG), Memória Visual (MV), Processamento Verbal (PV), Fluência Ideativa (FI) e Processamento Espacial (PE). As habilidades de segundo nível são: Rapidez Cognitiva (Gs), Fluência (Gr), Resolução de Problemas (Gf-Gc), Habilidade Visuo-Espacial (Gv) e Memória (Gy). A habilidade de terceiro nível é o Fator Geral (g). Foi julgada como variável dependente o escore total dos estudantes na prova do Enem de 2001.

\section{Consideraçóes Éticas da Pesquisa}

Os 45 testes cognitivos foram aplicados em seis ou sete baterias, dependendo da turma. Antes de responderem a qualquer tipo de instrumento da pesquisa, 
todos os participantes leram e assinaram um termo de consentimento livre e esclarecedor. Menores de idade deveriam trazê-lo assinado por um dos responsáveis. O tempo máximo de cada bateria foi de 70 minutos, mais 30 minutos para organizaçáo e gestão da sala, totalizando 100 minutos. Os estudantes que perdiam um teste, um conjunto deles ou uma ou mais baterias marcavam outro momento com o aplicador para que pudessem completar o que havia sido perdido. Os testes foram aplicados em horários de aula e dias letivos normais da escola dos participantes da pesquisa; no entanto, o aplicador combinava previamente com as turmas a sequência da aplicação, local, dia e hora. As datas e horários foram também antecipadamente combinados com os professores e os departamentos da escola, de forma a náo prejudicar o andamento do percurso escolar dos estudantes.

A prova objetiva de 2001 do Enem foi aplicada em um único encontro com no máximo quatro horas de duração e fora dos dias letivos escolares.

\section{RESULTADOS}

Apenas três habilidades cognitivas das 19 envolvidas tiveram relevância para a explicaçáo do desempenho dos estudantes na prova do Enem de 2001 (Tabela 1). Isso significa que o Enem de 2001 foi bastante seletivo, em termos dos processos cognitivos requeridos.

Tabela 1 - Como as habilidades cognitivas influenciam o resultado do Enem

\begin{tabular}{|c|c|c|c|c|c|c|c|c|c|}
\hline \multirow[t]{2}{*}{ Modelos } & \multirow[t]{2}{*}{$\mathbf{R}$} & \multirow{2}{*}{$\begin{array}{c}\mathbf{R} \\
\text { quadrado }\end{array}$} & \multirow{2}{*}{$\begin{array}{l}\text { R quadrado } \\
\text { ajustado }\end{array}$} & \multirow{2}{*}{$\begin{array}{c}\text { Erro padrão } \\
\text { das } \\
\text { estimativas }\end{array}$} & \multicolumn{5}{|c|}{ Estatísticas das mudanças } \\
\hline & & & & & $\begin{array}{l}\text { mudança no } \\
\text { R quadrado }\end{array}$ & $\begin{array}{c}\text { mudança } \\
\text { em F }\end{array}$ & $g \mid 1^{*}$ & $g \mid 2^{* *}$ & $\begin{array}{c}\text { Significância } \\
\text { das mudanças } \\
\text { em F }\end{array}$ \\
\hline 1 & $0,725(a)$ & 0,526 & 0,522 & 5,438 & 0,526 & 158,417 & 1 & 143 & 0,000 \\
\hline 2 & $0,760(b)$ & 0,578 & 0,572 & 5,147 & 0,052 & 17,582 & 1 & 142 & 0,000 \\
\hline 3 & $0,781(c)$ & 0,610 & 0,602 & 4,963 & 0,033 & 11,761 & 1 & 141 & 0,001 \\
\hline
\end{tabular}

Onde: $\quad$ * graus de liberdade - regressão

** graus de liberdade residual

a) Preditores: (Constante), RP.

b) Preditores: (Constante), RP, GS.

c) Preditores: (Constante), RP, GS, V.

Obs.: Variável Dependente: Enem.

Est. Aval. Educ., São Paulo, v. 20, n. 42, p. 73-88, jan./abr. 2009 • 79 
A habilidade de Resolução de Problemas (Gf-Gc) teve importância capital na explicação do desempenho dos participantes dessa pesquisa no Enem. Mais da metade da variância foi explicada por essa habilidade (52\%, mais precisamente). Essa evidência é relevante, pois indica que o Enem mobilizou intensamente, entre os participantes da pesquisa, a capacidade de resolver problemas, lidar com conteúdos abstratos, fazer inferências, estabelecer relaçóes lógicas e operar mentalmente tanto com conhecimentos prévios como com novos desafios e situaçóes em que os esquemas já aprendidos não são suficientes para a resolução dos problemas.

Além da Resolução de Problemas, a Rapidez Cognitiva (Gs) também foi responsável pelo desempenho dos estudantes no Enem. Sua participação, porém, foi bem mais discreta, explicando $5 \%$ da variância do desempenho dos participantes na prova. No entanto, essa porcentagem náo é irrelevante e indica que o Enem valoriza, pelo menos para esses participantes, certos automatismos.

A Rapidez Cognitiva é uma habilidade que indica uma série de processos cognitivos de velocidade de processamento em nível espacial, verbal, numérico, entre outros. Uma vez que o Enem foi explicado por essa habilidade, isso demonstra que possuir boa capacidade de processamento verbal e numérico, fazer contas rapidamente, saber ler com precisão e rapidez, etc. são componentes relevantes para o desempenho no Enem.

Além das duas habilidades destacadas, a Compreensão Verbal (V) também explicou o desempenho dos estudantes no Enem. Apesar de modesta (3\% da variância), essa participação não é desprezível e indica que o domínio do vocabulário, pelos estudantes, é um componente indispensável para o bom desempenho na prova do Enem.

Essa foi a única habilidade de primeiro nível do modelo de Carroll (1993) envolvida na explicação do Enem. Ela indica processos cognitivos bem mais específicos e especializados do que as outras duas habilidades, de modo que sua participaçáo no desempenho dos estudantes é muito significativa, mesmo que pequena em termos de explicação da variância. Por sua vez, as habilidades Resolução de Problemas (Gf-Gc) e Rapidez Cognitiva (Gs) indicam processos cognitivos amplos e genéricos.

As três habilidades cognitivas juntas explicaram $60 \%$ da variância do desempenho no Enem, um porcentual considerável. Esse resultado aponta que há forte associação entre a prova do Enem e as habilidades cognitivas. Isso corrobora a posiçáo defendida pelos formuladores do modelo teórico Enem (Macedo, 2005a, b, c) de que suas provas são elaboradas para mensurar modalidades estruturais da inteligência e que, possivelmente, o Enem seja um teste de inteligência a serviço da educação. 


\section{DISCUSSÃO}

As evidências obtidas neste estudo oferecem indícios de que a prova de 2001 do Enem pode ser tomada como um teste de inteligência. Aparentemente, os processos privilegiados são: Resolução de Problemas, Rapidez Cognitiva e Compreensão Verbal.

Devemos ressaltar que os resultados obtidos são derivados de uma amostra muito específica e com um tamanho reduzido de casos, o que dificulta a generalização das evidências construídas. Pelo caráter exploratório, as evidências encontradas fornecem pistas para novos estudos. No entanto, elas são representativas do universo $\mathrm{da}$ escola a que pertenciam os participantes da pesquisa. Uma vez que o Enem se propóe a ser um exame nacional válido para quaisquer ambientes escolares, acreditase que estudos localizados têm sua validade e indicam se a prova consegue alcançar os seus propósitos em contextos específicos, situados e bem circunscritos.

Respondendo à questão central deste texto - o Enem pode ser caracterizado como uma avaliação educacional construtivista? - podemos afirmar pelos resultados obtidos e sob certa perspectiva teórica, que sim. O desempenho dos estudantes na prova do Enem de 2001 foi explicado quase que exclusivamente pela habilidade de Resolução de Problemas (Gf-Gc). O construtivismo, na perspectiva dos formuladores do Enem (Macedo, 2005a,b,c), privilegia atividades de resolução de problemas, pois elas envolvem uma interação mais rica entre o sujeito e os objetos de conhecimento. Uma prova que ativa fundamentalmente processos de resolução de problemas pode ser entendida como uma prova que aprofunda a interação sujeito-objeto e demanda, por parte do aluno, processos cognitivos complexos e sofisticados. Esse tipo de prova é muito diferente, por exemplo, de outra focada na memorização, na mera explicitação de definiçóes conceituais, etc.

A habilidade Gf-Gc de nosso estudo representa os processos cognitivos da Inteligência Fluida e da Inteligência Cristalizada, ambas do segundo nível do modelo de Carroll (1993). Este autor obteve evidências de que testes de lápis e papel piagetianos são elementos da Inteligência Fluida, e em sua metanálise, demonstrou que tais testes estão situados no mesmo grupo dos testes psicométricos de lógica formal dedutiva e indutiva, e dos testes psicométricos de interpretação de enunciados lógico-matemáticos, de forma que as provas piagetianas representam a capacidade das pessoas em lidar com abstraçóes, formar novas relaçóes e resolver problemas em que os esquemas prévios não são suficientes.

A prova do Enem foi fortemente relacionada com a habilidade Gf-Gc, que, por sua vez, está relacionada aos processos cognitivos estudados por Piaget. Assim, po- 
de-se inferir que do ponto de vista dos processos cognitivos ativados a prova do Enem está no mesmo grupo de uma prova piagetiana.

Analisando outro argumento central do modelo teórico do Enem - de que suas provas avaliam componentes cognitivos fundamentais para o desenvolvimento da autonomia de pensamento e para a formação ao mundo do trabalho -, os resultados mostram que, aparentemente, o Enem faz o que promete. Baseamos essa conclusão na relaçáo encontrada entre a prova de 2001, a habilidade de Resoluçáo de Problemas e o fato de que, possivelmente, seja mais importante para o cidadão atual saber resolver problemas, pensar em nível abstrato, formar inferências e construir argumentos lógicos do que decorar informaçóes ou executar procedimentos mecanicamente, entre outros aspectos.

Além das questôes centrais relacionadas com a validade de construto, podemos argumentar a respeito de algumas implicaçóes educacionais em razão dos resultados obtidos. Apesar da ênfase na resolução de problemas, deve-se atentar para o fato de que a prova de 2001 esteve associada não somente a essa habilidade, mas também ao domínio de automatismos, como, por exemplo, memorizar fórmulas, ler com rapidez e fazer cálculos simples com eficiência.

Os resultados da prova de 2001 do Enem sugerem que a ênfase na resolução de problemas não prescinde do desenvolvimento de automatismos. Uma explicação possível para essa associação entre a Habilidade de Resolução de Problemas e a Rapidez Cognitiva, representando os processos automáticos, reside no fato de que estes liberam o foco de atençáo dos estudantes para os aspectos que realmente têm importância nos desafios dos problemas. Quando o aluno não domina certos automatismos, o seu foco de atenção volta-se para esses aspectos que deveriam ser automáticos, dificultando a tomada de consciência, a reflexão, o julgamento, entre outros processos que requerem muita atenção concentrada consciente.

Além disso, os processos automáticos não devem ser confundidos com a "decoreba". Os automatismos implicam que determinado conjunto de esquemas de ações se aglutine em um único processo, o que possibilita a diminuição da demanda de atenção consciente para o conjunto de açôes envolvidas. Lembrar de um conjunto de fórmulas, ler e fazer cálculos rapidamente, entre outros, são automatismos, pois envolvem um conjunto automático de açóes coordenadas que facilitam o processamento da ação. Ao contrário, a "decoreba" implica muito mais uma interação superficial, pobre e sem sentido entre o aluno e o objeto de conhecimento do que necessariamente uma relação direta com a produção de automatismos. Conforme argumentamos, os processos automáticos liberam parte 
da consciência para as demandas da resolução de problemas, de modo que não há uma relação direta entre eles e a "decoreba".

As evidências desta pesquisa mostram que parte do desempenho no Enem foi explicada pelo domínio de vocabulário dos estudantes, o que náo é surpresa. A prova é muito rica em informação verbal, na medida em que seus itens devem fornecer todas ou quase todas as informaçóes necessárias para a resolução do problema. Portanto, tentando priorizar a capacidade de pensar e náo a "decoreba", o Enem exige dos alunos bom domínio de vocabulário. Como os enunciados de seus itens são extensos, alunos com pior desempenho possivelmente têm menos vocabulário, e os que possuem boa prática de leitura têm mais chances de entender os enunciados e até definir melhor o que fazer, em razão do que é demandado pelo problema.

Outra implicação educacional importante diz respeito a que nem todas as habilidades cognitivas são essenciais para o rendimento escolar. Portanto, investir em componentes realmente indispensáveis parece mais sensato. No caso do desempenho no Enem, as intervençóes deveriam valorizar atividades que enfatizassem o desafio, incentivassem o aluno a formar novas relaçóes, a pensar de forma abstrata e ser capaz de utilizar e rearranjar os conhecimentos previamente adquiridos, que valorizassem o acesso do aluno ao mundo da leitura e da interpretação, assim como o desenvolvimento de certos automatismos.

Uma implicação ética, com base nos resultados encontrados, envolve o papel da escola no desenvolvimento da inteligência. Afinal: queremos apenas avaliar e não intervir, ou pretendemos fazer ambas as coisas? E, em função da pergunta anterior, a escola deve ser um lugar para desenvolver a inteligência? Analisando sob o ponto de vista prático, para que avaliamos modalidades estruturais da inteligência senáo para atuar nelas, uma vez que acreditamos que sáo componentes importantes para a formação dos estudantes?

Toda avaliação faz um convite explícito ou implícito para a intervenção. Não basta apenas mensurar certas modalidades estruturais da inteligência (as competências do Enem). A educação deve agir sobre elas. Nesse sentido, é de estranhar a existência de um sistema de avaliação do tipo do Enem e a baixa eficácia das políticas públicas voltadas para a concepçáo de planos para alterar o curso de desenvolvimento das modalidades estruturais da inteligência, como as Diretrizes Curriculares Nacionais de Ensino Médio.

Outra implicação educacional está relacionada à necessidade de articularmos mais incisivamente as avaliaçóes cognitivas às avaliaçóes escolares. Há estreita conexão entre a inteligência e uma série de processos demandados pela escola 
(Gottfredson, 2004). Conforme argumentam Reeve (2004) e McGrew e Flanagan (1997), durante um tempo considerável os estudos sobre a inteligência na escola foram tratados por pesquisadores que utilizavam quase que exclusivamente o teste de QI, ou poucos testes cognitivos, pressupondo que apenas o Fator Geral de inteligência explicaria o desempenho escolar.

Reeve (2004), assim como McGrew e Flanagan (1997), afirma que o modelo de inteligência presente no QI é muito rudimentar e antigo de forma que a escola estaria aproveitando pouco dos estudos mais recentes sobre a arquitetura intelectual humana. Eles defendem que os modelos mais atuais sejam incorporados nos estudos que articulam a inteligência com o desempenho escolar, pois descrevem com maior riqueza inúmeras habilidades cognitivas, em níveis distintos. Esses autores não argumentam sobre a realidade brasileira, mas podemos considerar que suas conclusóes também são válidas para este contexto.

Corroborando as impressóes desses autores, a utilização de um vasto conjunto de testes, capazes de identificar muitas habilidades cognitivas em níveis distintos, possibilitou-nos encontrar fortes relaçóes entre o Enem e processos cognitivos relacionados com as provas piagetianas. Se tivéssemos utilizado poucos testes, considerando que apenas o Fator Geral (g) explicaria o desempenho dos estudantes no Enem, não teríamos identificado a relação encontrada. Ao contrário, possivelmente estaríamos concluindo sobre a presença de uma relaçáo forte entre o Enem e o Fator Geral (g), o que acreditamos ser uma falsa conclusão, determinada pela ausência de variáveis cognitivas mais específicas.

Duas questóes finalizam este artigo. A primeira envolve o resultado de que o Fator Geral (g), controlado pelas habilidades do nível um e dois, não explicou parte do desempenho dos estudantes no Enem. Há muitas evidências na literatura internacional e nacional que contrapóem o resultado encontrado nesta pesquisa e relatam a existência de uma boa relação entre o Fator Geral (g) e o desempenho escolar.

Um argumento de Reeve (2004) ajuda a pensar essa questão. Segundo ele, quando elaboramos critérios bem específicos, circunscritos e detalhados sobre determinados processos, tendemos a identificar uma relação mais íntima entre esses processos e as habilidades cognitivas específicas, em detrimento do Fator Geral (g). Esse autor explica que esse fator tem grande poder de explicação em processos globais, em que o grau de especificidade não é muito alto. Não sabemos se este argumento é generalizável para outras situaçóes.

Se ligarmos os argumentos de Reeve aos nossos resultados, podemos especular que o Enem não foi explicado pelo Fator Geral (g), mas sim pela habilidade de 
resolver problemas, justamente por ser uma prova específica, elaborada para mensurar processos cognitivos específicos - resolução de problema, rapidez cognitiva e vocabulário. Em suma, o Enem é um bom indicador de processos de resolução de problema, como os envolvidos nas provas piagetianas. Se não fosse tão específico, ele seria melhor explicado pelo Fator Geral (g).

A segunda questão diz respeito à relação entre as provas do tipo do Enem e as provas escolares usuais. A escola avalia o progresso de seus alunos por meio de provas específicas, por disciplina. As notas dessas provas podem envolver a capacidade do aluno para lidar com novas informaçóes, cumprir prazos, trabalhar em equipe, interagir socialmente, respeitar a comunidade escolar, mostrar esforço e engajamento, etc. Por não conseguir distinguir as contribuiçóes dos diversos fatores que influenciam o desempenho escolar do aluno, a nota por disciplina é um indicador pouco preciso dos processos educacionais escolares. Entretanto, ela é valiosa por ser um indicativo sensível de problemas com o estudante, com a escola ou com a relação entre eles.

Apesar disso, é importante que a escola tente ampliar o seu grau de informação a respeito dos processos escolares, criando instrumentos mais precisos para acessá-los. A nota, por exemplo, não separa, com clareza, o conhecimento declarativo do conhecimento procedimental, ou a capacidade do estudante para formar novas relaçóes com base em um conteúdo já aprendido, da competência de utilizar o conteúdo já aprendido em situaçôes familiares, entre outros aspectos. Essas informaçóes mais específicas são valiosas para a escola e somente poderão ser obtidas com avaliaçóes mais específicas, por meio de procedimentos de validaçáo de instrumentos.

Um movimento, nesse sentido, vem sendo feito pela Psicologia nos estudos sobre a inteligência humana. Enquanto boa parte das pesquisas a esse respeito baseavase no teste do QI, medida rudimentar e pouco precisa, gradativamente há uma mudança sensível para a construção e validação de instrumentos mais específicos e precisos, capazes de identificar o universo multifacetado de habilidades cognitivas presentes na arquitetura intelectual. À medida que a Psicologia e a educação façam essas mudanças, é provável que essa elaboração identifique relaçóes mais refinadas entre componentes psicológicos e escolares, relaçôes essas que, no momento, são complicadas de se encontrar empiricamente. 


\section{REFERÊNCIAS BIBLIOGRÁFICAS}

BRASIL. Ministério da Educação. Instituto Nacional de Estudos e Pesquisas Educacionais Anísio Teixeira. Enem: documento básico. Brasília, 1998.

. Instituto Nacional de Estudos e

Pesquisas Educacionais Anísio Teixeira. Enem: documento básico. Brasília, 2000.

. Instituto Nacional de Estudos e

Pesquisas Educacionais Anísio Teixeira. Enem: relatório. Brasília, 2001.

CARROLL, J. B. Human cognitive abilities: a survey of factor analytic studies. New York: Cambridge University Press, 1993.

CONDEIXA, M. C. G. et al. Competência I. In: BRASIL. Ministério da Educação. Instituto Nacional de Estudos e Pesquisas Educacionais Anísio Teixeira. Exame Nacional do Ensino Médio (Enem): fundamentação teórico-metodológica. Brasília, 2005. p. 71-74.

FINI, M. E. Erros e acertos na elaboração de itens para a prova do Enem. In: BRASIL. Ministério da Educação. Instituto Nacional de Estudos e Pesquisas Educacionais Anísio Teixeira. Exame Nacional do Ensino Médio (Enem): fundamentação teórico-metodológica. Brasília, 2005. p. 101-106.

GOMES, C. M. A. Uma análise dos fatores cognitivos mensurados pelo Exame Nacional do Ensino Médio (Enem). 2005. Tese (Doutorado em Educação) - Universidade Federal de Minas Gerais. Belo Horizonte.

GOMES, C. M. A.; BORGES, O. N. Validação do modelo de inteligência de Carroll em uma amostra brasileira. Avaliação Psicológica, v. 6, n. 2, p. 167-179, 2007. Disponível em: <http:// www.scielo.br>.

GOTTFREDSON, L. S. Schools and the $\mathrm{g}$ factor. Wilson Quarterly, v. 28, n. 3, p. 35-45, 2004. Disponível em: <http://www.periodicos.capes. br>. Acesso em: 10 maio 2005.

MACEDO, L. de. Competências e habilidades: elementos para uma reflexão pedagógica. In: BRASIL. Ministério da Educação. Instituto Nacional de Estudos e Pesquisas Educacionais Anísio Teixeira. Exame Nacional do Ensino Médio
(Enem): fundamentação teórico-metodológica. Brasília, 2005a. p. 13-28.

Propostas para pensar sobre situações-problema. In: BRASIL. Ministério da Educação. Instituto Nacional de Estudos e Pesquisas Educacionais Anísio Teixeira. Exame Nacional do Ensino Médio (Enem): fundamentação teórico-metodológica. Brasília, 2005c. p. 37-39.

A Situação-problema como avaliação e como aprendizagem. In: BRASIL. Ministério da Educação. Instituto Nacional de Estudos e Pesquisas Educacionais Anísio Teixeira Exame Nacional do Ensino Médio (Enem): fundamentação teórico-metodológica. Brasília, 2005b. p. 29-36.

MACEDO, L. de et al. Competência III. In: BRASIL. Ministério da Educação. Instituto Nacional de Estudos e Pesquisas Educacionais Anísio Teixeira. Exame Nacional do Ensino Médio (Enem): fundamentação teórico-metodológica. Brasília, 2005. p. 79-88.

MACHADO, N. J. Interdisciplinaridade e contextuação. In: BRASIL. Ministério da Educação. Instituto Nacional de Estudos e Pesquisas Educacionais Anísio Teixeira. Exame Nacional do Ensino Médio (Enem): fundamentação teórico-metodológica. Brasília, 2005a. p. 41-53.

. Competência IV. In: BRASIL. Ministério da Educação. Instituto Nacional de Estudos e Pesquisas Educacionais Anísio Teixeira. Exame Nacional do Ensino Médio (Enem): fundamentação teórico-metodológica. Brasília, 2005b. p. 89-92.

MARTINO, M. C. et al. Competência V. In: BRASIL. Ministério da Educação.Instituto Nacional de Estudos e Pesquisas Educacionais Anísio Teixeira. Exame Nacional do Ensino Médio (Enem): fundamentação teórico-metodológica. Brasília, 2005. p. 93-98.

MCGREW, K. S.; FLANAGAN, D. P. Beyond g: the impact of Gf-Gc specific cognitive abilities research on the future use and interpretation of intelligence test batteries in the schools. 
School Psychology Review, v. 26, n. 2, 1997. Brasília, 2005. p. 75-78.

Disponível em: <http://www.periodicos.capes. MURRIE, Z. de F. A Área de linguagens e códigos br>. Acesso em: 10 maio 2005.

MENEZES, L. C. de. O Enem e os objetivos educacionais da área das ciências da natureza, matemática e suas tecnologias no ensino médio. In: BRASIL. Ministério da Educação. Instituto Nacional de Estudos e Pesquisas Educacionais Anísio Teixeira. Exame Nacional do Ensino Médio (Enem): fundamentação teórico-metodológica. Brasília, 2005. p. 61-64. MENEZES, L. C. de et al. Competência II. In: BRASIL. Ministério da Educação. Instituto Nacional de Estudos e Pesquisas Educacionais Anísio Teixeira. Exame Nacional do Ensino Médio (Enem): fundamentação teórico-metodológica. e suas tecnologias no Enem. In: BRASIL. Ministério da Educação. Instituto Nacional de Estudos e Pesquisas Educacionais Anísio Teixeira. Exame Nacional do Ensino Médio (Enem): fundamentação teórico-metodológica. Brasília, 2005. p. 57-60.

PRIMI, R. et al. Competências e habilidades cognitivas: diferentes definições dos mesmos construtos. Psicologia: teoria e pesquisa, v. 17, n. 2, p.151-159, 2001.

REEVE, C. L. Differential abilities antecedents of general and specific dimensions of declarative knowledge: more than g. Intelligence, v. 32, p. 621-652, 2004.

Recebido em: novembro 2007

Aprovado para publicação em: fevereiro 2009 
